\title{
Review of Schemes and Policies for Urban Transport in India with Reference to Socio-Equity Considerations
}

\author{
Prof. Rahul Tiwari, Assistant Professor, Department of Architecture and Planning, \\ Maulana Azad National Institute of Technology (MANIT), Bhopal, \\ ar.rahultiwari@gmail.com
}

\section{Dr. Yogesh K. Garg, Professor, Department of Architecture and Planning, Maulana Azad National Institute of Technology (MANIT), Bhopal, yogeshkgarg@gmail.com}

\author{
Ms. Utkarsha Negi, Investigator, Department of Architecture and Planning, \\ Maulana Azad National Institute of Technology (MANIT), Bhopal, \\ utkarshanegi95@gmail.com
}

\begin{abstract}
:
Public Transport has been seen since ages as the most environmentally sustainable mode of transport. The users of public transport are diverse and have different socio-economic character. Hence the public transport which is not only supposed to be environmentally sustainable but also envisaged to ensure equity amongst various stakeholders of society like the females, elderly and other vulnerable groups through its service. Gender in binary terms of being differentiated based on men and women is a social construct. Public transport systems in developing countries like India witness socio-cultural factors that shape the experience of women in public spaces by social norms extant in society. Along with this, gender-based issues related to public transport are social and behavioural shortcomings as a consequence of a lack of gender sensitivity. On similar lines, elderly have a negative experience involving safety threats, physical and psychological discomfort while accessing public transport systems. The literature published regarding such issues on the gender and elderly question in public transport systems have been studied and has been brought forth under a stand- alone narrative literature review. A literature review is a prerequisite to conducting either stand-alone reviews or as a preliminary study to be supported with quantitative or qualitative analysis. Here, a stand-alone literature review concerning issues in the public transport system in India has been performed. A narrative type of review is conducted to provide an overview of pre- existing published literature. Narrative overviews are useful educational articles as they help present a broad perspective on a topic and often define the development of a problem and/or ways to manage it. The semi-systematic or narrative-review approach is designed for topics that have been theorized differently and studied within diverse disciplines making it unfavourable to study under a full systematic-review process which majorly caters to reviewing quantitative researches. As narrative-styled literature reviews prefer a semi- systematic data collection method, utmost care has been taken to include perspectives from diverse disciplines. The scope of this review is restricted to summarizing the Indian policies, schemes of public transport in light of socio-equity consideration while narrowing the inherent discrepancies within the socio-cultural ethos of the Indian society which influences socio-equity consideration in public spaces in general and the modes of public transport in particular. Research articles from electronic databases were selected based on relevance to understand the issues this viewpoint, their essential findings and possible recommendations are formulated to provide a comprehensive summary of previous researches.
\end{abstract}

Keywords: Socio-Equity, Urban Transport, Policies, India

\section{Introduction to Equity in Transport:}

Equity refers to the fairness in distributing impacts which comprises of both costs and benefits. A better linked transport system would not only allow growth to the people who reside near the hustling hubs of cities, but people living on the peripheries can also get an access to participate. Transport is not the only way to build an equitable society; rather it is just an aspect in understanding the implications of inherent divisions existing in the society. These divisive factors could be as wide ranging as being economic, that is lower income groups and affluent sections; social in terms of race, ethnicity, caste, gender; ability with an emphasis on differently abled people. With proper policies which consider these impacts, when 
implemented can surely pave the way for a just and equitable society. Equity should maximize average accessibility and minimize disparities between the higher and the lower rungs of our society (Martens, Golub, \&amp; Robinson, 2012). Equality is different from equity as the latter focuses on making concessions and distributions of costs and benefits respectively while aiming for the larger fairness to be achieved through these means. Equity when considered with keeping in mind the multiple impacts and ways to the different ways to measure it, it becomes obvious that the quest for an equitable transport is a trade-off between equity objectives and planning objectives (Litman, 2020). Equity can be horizontal equity where the distribution of impacts are among individuals and groups who should be treated as equals or vertical equity which implies the distribution of impacts between individuals and groups who differ in terms of social class. Horizontal equity focuses on fairness which does not favour anyone over others while vertical equity is considered to be more 'progressive' as it stands for preferential treatment for the disadvantaged groups. Transport policies become equitable in different terms as defining equity is difficult, a policy may stand equitable in one sense and be differing the idea of equity in the other. Some policies may exhibit a stand in progressive terms to acknowledge the vulnerabilities of the people who are the target groups of these policies. The quality of transport available to people affects their socioeconomic standing in the society.

Economic impacts of an equitable transport system would focus on minimizing the ineptness of poor connectivity in order to give people a new horizon to explore economic opportunities such as getting education or finding jobs. Urban transport has the need to undertake studies which highlight the shortcomings of an inequitable transport system as it is an important tool to move in the direction of creating an equitable society. With good transport, the dichotomy between accessibility and mobility, two most important factors for creating equitable urban spaces can be achieved. There are different types of equity and something which is equitable in one aspect may not be so in another. Keeping up with the debate of mobility versus accessibility, transport planning has conventionally favoured augmented levels of mobility, initially concerning highway capacity for the private car, but has shifted increasingly with infrastructure for public transport, walking and cycling (Hickman, Lira, Givoni, \&amp; Geurs, 2019) . While the history of transport shows that mobility has been preferred over accessibility, it cannot be refuted that with sustainability and equity considerations taking centre-stage this debate has been further extended. .

Mobility allows people reach places is an end in itself while the larger goal of transport is accessibility as it allows people be capable of reaching destinations that may cater to their growth for instance accessibility to reach a place of education is of more importance and has far reaching effects as it involves opening up of spaces of interaction with the people which may have been historically absent. Accessibility in turn is affected by many factors which includes mobility (Litman, 2003). For example, in order to provide basic mobility to people the National Urban Transport Policy along with the Jawaharlal Nehru National Urban Renewal Mission, the Bus Rapid Transit Systems (BRTS) have increased the reach of the people providing them with mobility and since mobility is positively linked with socio-economic growth, transport becomes a torchbearer of bringing in social equity concerns on the urban transport scenario in India which was gripped with a boom of motorised vehicles which was deemed to be a precursor to economic development. While the affluent section participates in motorised transit, there remain factors which discourage the low income group people from realising better opportunities. The disadvantaged group consists of low income groups, women, children, Non Motorised Transport (NMT) users, pedestrians and people suffering with physical disabilities. As these are divisions which are socio-cultural and economic in their origins, they also remain visible in transport equity analyses.

Programmatic solutions and structural solutions can help alleviate the problems of equity in urban transport. While a programmatic solution would cater to only the target group, as in the case of providing seats or coaches reserved for women on public transit; a structural solution means the investment done in coherence with equity considerations in transport as a means have an overall benefit to the users. Various theories of justice including Rawl's Capability Approach principle is found to be based on an evaluation of equity with focuses on the disadvantaged group's accessibility on basic services, reduce transport 
externalities and promote individual rights (Pareira, Schwanen, \&amp; Banister, 2016) . Vertical equity is more apt for the Indian scenario where a large number of people using public transit are of lower income groups. This renders them more vulnerable and a motorised vehicle centric policy would mean a promotion of the interest of the upper class people excluding a large chunk from attaining access to opportunities. Transportation price increases are often deemed to be regressive, as high fares represents a larger share of income for lower-income people than for higher- income people. Overall equity impacts depend on who would pay the tolls, how prices are structured, the quality of transport alternatives available (Manville, 2017)

Usage of a multi modal transport system would highlight the goal of integrating trips in order to provide an interconnected transport model. While emphasis on the NMT modes is the marker of progressive outlook of the policy makers to promote vertical equity, it still remains a neglected area within the sphere of policy implementation. The vulnerable road users are recognised and to work for trying to implement transport equity analysis into study of distribution of impacts remains crucial. For instance, in Ahmedabad, the integration of the BRTS with existing municipal bus services did not happen. (Mahadevia, Joshi, Datey, 2013) Some Indian cities have developed bicycle facilities as part of transportation improvement programs but this still remain a roadblock on the way to integrate the population that depends on NMT modes of transit. It is necessary to incorporate equity in all phases of decision making. When identifying a target group within population for the analysis along with considering their needs, to develop strategies to curb such disparities is the most important stage of equity analysis. As consideration of vulnerability is higher for low income groups and other disadvantaged groups, they remain more prone to undergoing the brunt of the multiple impacts of an inequitable transport system. High prices of fare, ill quality of air due to obsolete means of transport, unsafe road use because of their dependence on NMT modes such as walking are all the examples for the above.

\section{National Urban Transport Policy 2oo6:}

The National Urban Transport Policy (NUTP), 2006 has been a major landmark event in recognising the persistent issues with urban transport and bringing in social equity considerations. Until NUTP the problematic areas of city transit such as congestion, air pollution, and increasing road accidents had not been looked upon. As India's population and urbanization process had just begun to pace up following the liberalization of 1992, new issues regarding urban transport became evident. The rapid increase in the number of vehicles on road during the early 2000 s because of cheaper fuels, cars and motor bikes, the country saw a rise in the number of vehicles from 0.3 million to 55 million between 1951 and 2001 and then to 90 million in 2006. While India's urban population was low it was set to double in the coming 30 years and this demanded for swift action (Ramachandran, 2016). This paved the way for NUTP to be formulated. Key considerations of National Urban Transport Policy (MoUD, 2007) in terms of social equity are living up to the ideal of 'moving people rather than vehicles',

1. In a first of such attempts to understand the plight of the considerable chunk of the population which depends on Non-Motorised Transport (NMT) modes, the policy acknowledges them as vulnerable road users.

2. The difference in the levels of service to be provided to people from different income groups, equitable and subsidized fares for lower income groups without compromising with the quality of transport and exemption of subsidy from those who can afford.

3. It proposes for allocation of separate exclusive lanes for public transport and NMT modes in order to prevent congestion on the road. It also calls for innovation in infrastructure such as a shade giving landscape, resting areas etc.

4. Different technologies according to the landscape and needs of the city, as it proposes to inculcate best practices from around the world for adopting a public transport system, it is also aware of the unique needs of urban transit in India.

5. For equitable allocation of road space coupled with financial aid from National Urban Renewal Mission (NURM), construction of cycle tracks to be promoted. 
6. Sustainability and exploring 'green travel habits'

7. Capacity building and public awareness: providing fillip to knowledge creation in this regard and to make people aware of their participation in the urban public transport scenario.

With rapid economic growth, there is a surety of migrations happening towards urban areas and that the cities witness spreading and urban sprawling. Keeping this in mind, the NUTP recognised a timely need for a policy that makes urban spaces ready for such future developments. As per the growing prospect of urbanization, cities are required to be prepared to meet not only the mobility needs of the population but also provide for the needs for those yet to join the urban population (MoUD, 2007). Equitable allocation of road space is the contribution of NUTP 2006 for giving priority to sustainable and inclusive forms of transport. Reserving separate lanes for buses as in the Bus Rapid Transit System taken up by a few cities, financial support was drawn from the JnNURM scheme.

This policy was proposed for promoting public transport when there was a sudden surge in the number of privately owned vehicles which added on to the congestion on road. As no provision for allocating separate lanes for the slow moving commuters on road existed, increase in the number of vehicles became problematic for such vulnerable groups accessing the road. Pedestrians and cyclists remain even more unsafe because of the comparatively higher threat they remain under, the number of road accident deaths went up from 28,400 in 1981 to 80,000 in 2001 (Ramachandran, 2016). The majority of pedestrians walking to work places do so because they are compelled out of their low incomes and with no due road space being provided, they are remain vulnerable. The hustle of an urban road includes a haphazard congestion of pedestrians, randomly parked vehicles, cyclists, vendors and small road-side shops. The urban cities witness that there is a strong economy that runs by the roadside where pedestrians participate (Sharma, 2010). This points out that pedestrians and cyclists need to be provided with safeguards and appropriate legislations to protect them. Even though NMT modes are more environmentally friendly and affordable people from lower income groups do not choose 1 it, rather they are left with no equitable options. So NUTP mentions the creation of segregated rights of way for bicycles and pedestrians in order to counter these issues pertaining to social equity.

The combination of non-motorised transport network, segregated cycle tracks, footpaths do not exist in most of the places and because of no proper parking space, the cycle lanes are used for parking vehicles which in turn causes the cyclists inconvenience (Mahadevia, et al., 2015). This also brings us to notice the attitude associated to cycle lanes and in the hierarchy of vehicles, pedestrians and cyclists are at the lower rungs. The appropriation of such allotted spaces by people to use for any other reason than maintaining it solely for cyclists and pedestrians shows that at the ground level people are not aware of the usage of such construction. In order to not remain merely a document of guidelines, by creating awareness about the usability of the allocated road space the ideals of the policy can be realised with time. An "inclusive roads" in an Indian urban context would be one which accommodates pedestrians, cycle rickshaws, bicyclists and street vendors. While recognizing the quality concerns of the public transport systems in India, NUTP led to opening of new channels of discussion and deliberations regarding the situation of urban transport in India. The collaboration of the NUTP and the National Urban Renewal Mission created a partnership between the different levels of government so as to facilitate future course of actions as well. This remains unaffected by changing governments (Ramachandran, 2016).

\section{Jawaharlal Nehru National Urban Renewal Mission (JnNURM):}

Jawaharlal Nehru National Urban Renewal Mission was a joint mission of the Ministry of Urban Development (MoUD) and the Ministry of Housing and Urban Poverty Alleviation (MoHUPA) aimed at providing a universal access of civic amenities and utilities to the urban population. It started in 2005-6 and proposed to be a seven year endeavour; it was extended for two more years to be followed by other urban planning schemes like Atal Mission for Rejuvenation and Urban Transformation (2015) and Smart City Mission (2015). The mission statement of JnNURM highlights an ambition to provide all urban residents an access to basic level of urban services. While it aims at an establishment of linkages between asset-creation and asset-management through reforms for long-term project sustainability, in 
transportation it remains confined to the procurement of city buses. It resulted in boosting the public transportation system by linking old city area dwellers to the hub of the city. Along with JnNURM, the National Urban Transportation Policy (NUTP) of 2006 has enhanced urban public transportation projects and proposed new avenues for social equity considerations to make urban transportation pro-pedestrians and pro-cyclists. With allocation of funds for the Bus Rapid Transit (BRT) projects in several cities, the objective of making transportation more people-centric rather than vehicle-centric as guided by the NUTP, 2006 has been realised by providing accessibility and mobility to the people.

The bus based public transport system when provided with dedicated lanes has allowed a faster transit, and has created suitable environment for providing social equity. Transportation can act as a major link facilitating the urban poor, women, and other vulnerable sections with mobility which earlier remained restricted. Commuters of low income groups, women, children, and differently abled persons are the vulnerable groups who need representation while formulating an urban transportation policy as each of these mentioned groups face unique challenges while travelling. For instance, the societal restrictions put on women to discourage their participation in the public spaces are reinforced when women give up opportunities of growth due to unsafe travel experiences. Whereas women face issues which require behavioural changes in terms of providing a safe environment for them to access public transportation, women of lower income groups face double the agony to give up a large portion of their incomes on transportation costs. This highlights the intersections of inequalities that act on individuals and that the unique issues of each city can be brought to consideration by schemes like JnNURM. Although in terms of equity, transportation is not an end in itself, rather it can be a tool for levelling the persistent disparities. The end is to cater better opportunities and appropriation of space in order to have an inclusive society. The importance of such social equity considerations lies within the scope of policy making to benefit the public by representing and recognising their needs to access public spaces.

In a case study on Ahmedabad BRT system, it was found that among the urban poor with household incomes less than Rs 5,00o per month, half walked to stations, one-third took the Ahmedabad Municipal Transport Service buses or shared an auto, and 11\%, who were long- distance commuters used either the railway or state transport to reach the BRT system. Only $2.8 \%$ used motorised two-wheelers. It shows that for lower income group commuters who would possibly travel for work had no other option but to spend an added amount of time and money in order to reach the BRTS buses and this was majorly possible the male workers. And since the cost of reaching a workplace is a cumulative of different trips that are made in order to access the BRTS buses, people preferred to conduct more than $80 \%$ of their total trip by BRTS (Mahadevia, Joshi, Datey, 2013). This reinforces the notion that even though the JnNURM funded buses allow mobility and opened avenues for people to reclaim their space which was earlier limited due to class and gender biases, the contribution of this scheme for promoting social equity in its true sense still remains ambiguous.

To curb the safety threats women face while using public transport, the joint work of JnNURM and Uttar Pradesh State Road Transport Corporation (UPSRTC) in Lucknow had brought out a few ladies special buses called 'Sakhi'. The study on this initiative revealed that $40 \%$ of women approved of it and as much as $50 \%$ of men strongly opposed this initiative (Gufran, Amir, 2012). This highlights the attitudes regarding women's mobility and the taboos attached to the then initiative and that positive discrimination is met with societal disapproval and the need for initiatives for vulnerable groups are deemed to be unnecessary. There still remains scope for improvement of taking the initiatives under JnNURM of BRTS buses to add on new benchmarks to make it more socially inclusive to access and promote social equity on the lines of imbibing best practices of transportation from across the world. Special attention should be given to the vulnerable section which remains unsafe due to the inherent impediments existing on our way to a just and equitable society. The differences in incomes or areas of settlement should not be allowed to act as an inhibiting factor from achieving both social equity and economic growth. As with JnNURM, the focus was on to create a better access and mobility to all urban people, it still remains a pertinent issue that urban renewal which comprises of factors like improving sanitation and housing which in fact play an important role in improving the quality of life. 


\section{Bus Rapid Transit System (BRTS):}

Public Transport plays a huge role in urban development as it facilitates the easy flow of goods and people from the periphery to the city centres. Urban centres are the places of economic activity and the hustle of the city provides opportunities that can boost levels of economic activity. For achieving equitable and sustainable measure to meet the demands of urban transport in India, the BRTS acts as a viable solution. With the coming of JnNURM (2005) and the National Urban Transport Policy of 2006, the focus has shifted from a vehicle- centric transport to a people-centric transport in urban areas. For providing a basic level of sustenance to the urban poor, considering equity has taken centre stage. The Bus Rapid Transit System (BRTS) traces its popularity from Bogotá's world famous system Transmilenio. The aim of a bus based Mass Rapid Transit System (MRTS) is to ensure that maximum number of people can travel in minimum time and affordable fares. As the metro based MRTS takes a lot of financial assistance and has a longer gestation period, it fails to address the present issues of urban transport in India. In order to do away with issues of congestion because of growing population, increasing number of private owned vehicles and environmental concerns regarding increasing emissions due to these factors, it becomes important to invest in a mass rapid transit system that caters to the needs of the public. The BRT system comes to the rescue as it can be as efficient as a metro based MRTS and requires less investment in comparison to it.

A key feature of this system is the dedicated right of way assigned as in the Indian case, an open BRT system is made as a network facilitating easy access to urban areas. While some models like the Ahmedabad 'Janmarg' has successfully created such network of BRT lanes, the other cities where BRTS was constructed, have seen a shortfall in creating the desired infrastructure, rather now the bus lanes exist in the middle of only busy roads as allotted space for it to function is only in selected locations. This breaks the continuity and in turn does not address the aim of attracting more and more people to use this public transit. The modal shift from private vehicles to BRTS would work in favour of forming both an equitable and sustainable society when there is attitudinal change brought by adequate awareness among the people. As road space in India is shared by Private Motor Transport (PMT) vehicles as well as the public transit, it is also occupied with slow moving pedestrians, non- motorised transit users and informal workers such as street vendors. The planning of BRTS as such requires an inclusion of the concerns of all such vulnerable road users. In terms of providing for an inclusive mode of transport, the BRT system has surely enhanced women's participation in the public realm while they continue to face problems typical to gender based insecurity and threat that women undergo while using public transport. Public transit allows space for some measures that can be taken in this direction, even though they fail to cater to ensure a maximum safe environment for women commuters. Public transport even though crowded, they can still implement some infrastructural changes and introduce safeguards which can enhance women's travel experience. Issues pertaining to BRT System that are gendered unfavourably for women are of grave importance in order to promote social equity. Planning for a safe and inclusive transport which is womenfriendly can happen at three levels: street design, public transport infrastructure and land use planning (Murthy, 2011).

While public transport infrastructure has seen some changes such as women only seating, separate coaches for women in metro MRTS etc. there still remains issues which needs to be addressed. One such issue is the less frequency of buses running. This forces women to resort to para-transit modes which in turn are highly unsafe. As an integrated feeder and BRT system is not present, infrastructural changes taken at the BRTS level such as use of CCTV surveillance cameras in the bus and GPS tracing, women are to step out and take other para-transit modes such as autos, minivans etc. While in a study of Bhopal BRTS when paralleled to Pune PMPML, it was found that women in Bhopal would rather choose paratransit options instead of BRTS even though the security risk remained higher there (Mahadevia, Bhatia, Sebastian, 2019). These are not guarded with any legal safeguards rendering women highly unsafe. The chances of sexual harassment remains high in a crowded para-transit vehicle and identifying and reporting the harassers becomes a difficult task, leaving women to resort on keeping silence on such incidents. Violence on the road is governed due to the lack of any institutional mechanism to prevent 
conflicts from happening threatening women's safety. Many of the non-state actors have political links and they add to the unsafe environment. (Mahadevia, Desai, 2019). The BRTS has a gendered reach among the public as there remains disparities between genders on how much they access it. Only $55 \%$ of men were found to be travelling for work via BRTS in a study conducted at Ahmedabad, while women continued to travel for other purposes (Mahadevia, Joshi, Datey, 2013) .

With all the merits of a BRT system, integrated transport is of importance as it still does not bridge the gap between the urban poor and equitable transport. In a case study of Ahmedabad BRTS, it was found that while it remains unaffordable for lower income group people and for women of lower income groups it was particularly so (Mahadevia, Joshi, Datey, 2012). This shows that women have to undergo double the brunt of inequity which limits them from a fair access to public transport. Forced reduction on mobility of women are a marker of inaccessibility which they face on top of an unsafe environment. As a way forward, the BRTS while acting as a tool to achieve higher mobility, needs to be developed in a way that accommodates the economically disadvantaged as it is them who are needed to be provided with an equitable transport option. Even with economic growth, motorised transport should not be made a resort to the population for sustainability and social equity reasons.

\section{Mass Rapid Transit System (MRTS):}

MRTS is a transport system that caters to a larger number of people providing them access to places in minimum duration of time. MRT System may be based on rail or bus and both serve the purpose of commuting maximum number of passengers in minimum duration of time (Vats, 2015). It is a complex and capital intensive process and takes a longer gestation period before it starts benefitting the people. Since it requires a large amount of investment, a variety of public-private partnership models (PPP) are used. To make better use of scarce urban spaces, MRTS offers public transport options with separate rights of way easing the problems of on road congestion and pollution in the form of BRTS, rail metros, regional rails, and light rail transits (LRT). This helps in an equitable allocation of road space as it facilitates a transport corridor which reduces the chances of accidents. While considering rail metro, he multiple advantages are as noted, 'Metro rail projects provide larger economic and social benefits to the society in terms of reduction in cost and time of travel, substantial reduction in per capita pollution emissions resulting in reduction in chronic diseases, reduction in road accidents, bringing down noise pollution' (MoHUA, 2017). With growing population and movement of people into the urban areas, there is a need for a MRTS as it becomes a sustainable and economically viable option when commuting for a longer distance. Connecting the peri-urban areas to the city centres is an important task with respect to urbanization and migration of people to urban centres. While affordability of living in major urban cities remains unfavourable, it is expected out of a public transport system to cater to the needs of different income groups in a qualitatively alike manner.

Investment in MRTS expands the importance of having an inclusive urban space accommodating an urban population in order to facilitate economic growth and activity. With MRTS providing for a fast, affordable transport of people from such census towns and peripheries, it can be said that the equitable allocation of already deficient land- use in urban spaces could be met with a sustainable counter (Ranjan, 2018). Metro rail can have a very high capacity of 40,000-80,000 passengers per hour per direction (PPHPD) which adds to an improved mobility in urban spaces (Ranjan, 2018). With the coming of metros, there is also a growth of new business centres which promotes urban expansion. As with increased mobility, urbanization, and accessibility provided by MRTS, commercial activities flourish. Economic growth is connected to mobility aspect of transport as far away areas were now within the reach of commuters to discover job and education opportunities. Local markets would also grow as with increased mobility there would be an increase in the number of consumers. MRTS attempts to offer maximum connectivity in minimum fares of transport. MRTS for an inclusive development can be a great tool to inculcate social equity considerations within the ambit of urban planning as it enhances mobility, opening up avenues for urbanization. Since efficient urbanization is significant for achieving higher growth rate, it is also recognise the divisions persisting in the society. This would allow policy makers to 
consider the issues of vulnerable section while introducing new urban transport modes. In order to accommodate the demands of urbanization in terms of horizontal spread of urban centres and in-flow of people to these centres, longer stretch of distance is needed to be travelled by the inhabitants of such urban areas. MRTS comes to the rescue to avoid problems of congestion, haphazard allocation of road space and no attention to the needs of Vulnerable Road Users (VRUs) such as pedestrians and NonMotor transit (NMT) modes of transport. Urban sprawling and land-use for building such infrastructure is also an area where the overcrowding and unfair allocation of road space is pertinent. On the other hand, it is also a reality that with cities spreading horizontally, the connectivity between far flung areas and city centres becomes a necessity of the hour. Although in India, a lot many other factors come into play while assessing the usability of such transit modes. BRTS is a viable option for cities in India as it does not require as much time as a metro project to come into fruition while it furnishes to the demands of urban transport system in India. In Indian scenario, cost overrunning and underutilization of capacity of MRTS (such as rail metros) is an obstruction for an equitable mode of transport. While acceptability and affordability are the merits of introducing a system like MRTS, BRTS models come in handy in terms of the requirements of Indian urban spaces as such Indian transport has been heavily dominated by bus services while in terms of sustainability advantage of MRTS remains in the fact that it requires $1 / 5$ th energy per passenger $\mathrm{km}$ as compared to that of a road- based transport systems (Vats, 2015).

\section{Review Conclusions:}

While inequities persist in our society at multiple levels and multifaceted overlapping factors account to them, it becomes evident as to why transport equity is a tough task to define and to interpret (Litman, 2020). In transportation, equity plays an important role as it remains an unavoidable aspect of transportation planning. It is a tedious task to understand equity in transport as most of the impacts are multifaceted overlapping outcomes of the existing system of transport coupled with transport policies. These impacts are various and are to be analysed and measured differently. Governance still remains fragmented the implementation of this policy as only a few cities responded well in line with this policy. The Ahmedabad BRTS model is lauded around the world, though the bottleneck of such policies lies at the restricted implementations. Only multi-million cities benefitted out of this and most depended on the local authorities to show participation and interest. Lack of strict enforcement has made these infrastructural innovations come to a deadlock with attitudinal changes expected out of the public (Kuriakose, 2013). The latter cannot be possible without awareness programs to make people understand the problems and threats the vulnerable road users are exposed to and what the government effort of separate allocation of right of ways is for their better commute experience. The aspects provided by the policy needs to be implemented at the local level so that people would be made aware of the usability of such measures to be taken in order to avoid the problems of urban transit. Even if connectivity is provided the created network might not be used until there is an attitudinal change and awareness on the users end. An integrated master-plan needs to address to such issues as well as to internalise sustainability (Quigley, et al., 2012).

For instance they could be external impacts such as pollution and problems of congestion, while economic impacts would cater to the accessibility of education and employment opportunities. Both of these equity considerations are important as they have far reaching effects on the lives of people. While the former deals with building an equitable network of transport that showcases judicious land-use, minimises pollution and lowers the increasing number of motorised transit the later remains a pertinent impact as well. In a comparative study of the BRTS of Ahmedabad called "Janmarg" and the Delhi Metro to understand the implications of the two kinds of mass rapid transit systems, it was found that both were working in accordance with the National Urban Transport Policy 2006 which suggested that technologically improved modes of public transport should be used as per the requirements of each city. Both of these developments had the backing of national policies (Bhandari, Kato, Hayashi, 2009). The equity concerns of both the projects have assumed that public transport needs to be subsidized in order to be equitable; however, collectively this system becomes expensive for lower income groups. The reality 
remains that it is necessary to subsidize public transport operations even in the most favourable environments (Tang, Lo, 2010).

\section{Funding Acknowledgement:}

This paper is an outcome of Research Project funded by the Indian Council for Social Science and Research (ICSSR), New Delhi, titled 'Exploring Social Equity issues of present Urban Transport Scenario in Indian context', File No. 02/165/2019-2020/MN/ICSSR/RP; dated: 31 October 2019.

\section{Bibliography:}

Boer, \&amp; M. D. Zaaroura, Reducing Urban Violence in the Global South: Towards Safe and Inclusive Cities (p. 177). Routledge.

Bullard, R., \&amp; Johnson, G. (1997). Just Transportation; Dismantling Race \&amp; Class Barriers to Mobility, New Society Publishing.

Bhandari, K., Kato, H., \&amp; Hayashi, Y. (2009). Economic and equity evaluation of Delhi Metro. International Journal of Urban Sciences, 187-203.

Bhattacharya, A., \&amp; Mahapatra, G. D. (2017). Urban Governance in Multimodal Integrated Urban Transportation. International Journal of Multidisciplinary and Scientific Emerging Research, 100-107.

Datey, A., Darji, V., Patel, T., \&amp; Mahadevia, D. (2012). Walking and Cycling in Indian Cities: A Struggle for Reclaiming Road Edges. Promoting Low Carbon Transportation in India. UNEP.

Dave, J., \&amp; Arora, K. (2015, October). Interventions by the Self Employed Women's Association (SEWA) in Ahmedabad, India. Women in informal Employment: Globalising and Organising. Inclusive Cities Project.

Gufran, A., \&amp; Amir., Z. (2012, January). Review of City Bus Transportation under JNNURM: A Study of Lucknow City. Viewpoint, pp. 10-22.

Gunatilaka, R. (2013). To work or not to work?: Factors holding women back from market work in Sri Lanka. International Labour Organization, ILO DWT for South Asia and Country Office for India.

Hoyez, M., \&amp; Martin, M. (2014). Urban transport in India: A developing network. CODATU.

Hickman, R., Lira, M. B., Givoni, M., \&amp; Geurs, K. (2019). Transport and space and social equity impacts. In A Companion to Transport, Space and Equity (pp. 2-7). Elgar Online.

Joshi, R., \&amp; Joseph, Y. (2015). Invisible Cyclist Disappearing Cyles: The challenge of cycling policies in Indian Cities. Transfers inderdisciplinary journal ofmobility studies, 29-31.

Kuriakose, P. N. (2013). National transport Policy of India: Organization, Issues and Bottlenecks for Implementation. Institute of Town Planning, India Journal, 52-58.

Khosla, R. (2009). Addressing Gender Concerns in India\&\#39;s Urban Renewal Mission. New Delhi: UNDP.

Kumar, D. A. (2006). 'Equitable policies, inequitable outcomes and inequitable polices and inequitable outcomes: A case of land, housing and transport in Delhi. ITPI Journal, 1- 14.

Levy, D. K., McDade, Z., \&amp; Dumlao, K. (2010). Effects from Living in Mixed- Income Communities for LowIncome Families: A Review of the Literature. Urban Institute.

Litman, T. (2003). Measuring Transportation: Traffic, Mobility and Accessibility. ITE Journal, 28-32. 
Litman, T. (2020). Evaluating Transportation Equity Guidance for Incorporating Distributional Impacts In Transportation and Planning. Victoria Transport Policy Institute.

MoHUA. (2017). Metro Rail Policy. Ministry of Housing and Urban Affairs.

Murty, M. N., Dhavala, K. K., Ghosh, M., \&amp; Singh, R. (2006). Social Cost-Benefit Analysis of Delhi Metro. Delhi: Munich Personal RePEc Archive.

Mahadevia, D. (2015). Promoting Low Carbon Transport in India- Gender Sensitive Transport Planning for cities in India. New Delhi: Magnum Custom Publishing.

Mahadevia, D., Bhatia, N., \&amp; Sebastian, R. (2019). Gender Responsive Budgeting for Indian Cities: The Case of Bhopal and Pune. SAGE, 44-61.

Mahadevia, D., Joshi, R.; Datey, A. (2013, November 30). Ahmedabad's BRT System- A Sustainable Urban Transport Panacea? Economic; Political Weekly, pp. 56-63.

Mahadevia, D., Joshi, R., \&amp; Datey, A. (2012). Accessibility and sustainability of bus rapid transit in India. Roskilde: UNEP Rise Centre on Energy, Climate and Sustainable Development, Technical University of Denmark.

Murthy, K. (2011). Urban Transport and the right to the city, accessibility and mobility. In M.-H. Zerah, V. Dupont, \&amp; S. T. Rewal, Urban Policies and the Right to the City in India: Rights, Responsibilities and Citizenship, UNESCO, INDIA and CSH, India (pp. 122-132).

Manville, M. (2017, August 15). Is Congestion Pricing Fair to the Poor? Retrieved August 16, 2020, from 100 Hours: https://medium.com/10o-hours/is-congestion-pricing-fair-to-the-poor-62e281924ca3

Martens, K., Golub, A.; Robinson, G. (2012). Justice-Theoretic Approach To The Distribution Of Transportation Benefits: Implications For Transportation Planning Practice In The United States. Transportation Research Part A: Policy and Practice, 684-695.

Pareira, R. H., Schwanen, T., \&amp; Banister, D. (2016). Distributive Justice and Equity in Transportation. Transport Reviews, 1-22.

Quigley, C., Sims, R., Hill, J., Tripodi, A., Persia, L., Pietrantonio, H., et al. (2012). Transport Planning Guidelines for Vulnerable Road User Safety in Emerging Economies. Transport Research Arena 2012 (pp. 3220-3228). Elsevier Ltd.

Ramachandran, M. (2016). Reforming Urban Transport in India: Issues and Best Practices. Ghaziabad: COPAL Publishing.

Ramanathan, A.; Paul, S. (2018). The effect of urban infrastructure development on female labour force participation among the poor and middle class in India. Texas USA: Woodstock.

Ranjan, R. (2018). Mass Rapid Transportation Systems in India. Mass Rapid Transportation Systems for Urban Area: Opportunities and Challenges. Kolkata.

Rizvi, A. (2013). Alternative Approaches to Economically Sustainable Mobility in India: Comparing Ahmedabad Bus Rapid Transit and Delhi Metro Systems. Global Report on Human Settlements 2013.

Sharma, T. (2010). The hierarchy of mobility. Janaagraha Centre for Citizenship and Democracy, India.

Singh, Y. P., \&amp; Kashyap, B. K. (2016). Mass Rapid Transit System- An Emerging Mode Of Public Transport. Scholarly Research Journal For Humanity Science \&amp; English Language, 3254-3260. 
Twaddell, H., \&amp; Zgoda, B. (2020). Equity Analysis in Regional Transportation Planning processes. National Academies of Sciences, Engineering, and Medicine. Washington, DC: The National Academies Press.

Tiwari, G. (2002). Urban Transport for Growing Cities: High Capacity Bus Systems. New Delhi: McMillan.

Tang, S. B., Lo, H. K. (2010). On the financial viability of mass transit development: the case of Hong Kong. Transportation, 299-310.

Thynell, M. (2007). Social Change and Urban Transport. Bonn: GTZ.

Vats, K. A. (2015). MRTS- A Sustainable Transport System. 8th International Conference on Recent Advances in "Civil Engineering, Architecture and Environmental Engineering for Sustainable Development, (pp. 48-51). New Delhi.

Wankhede, K., Anand, G., Sen, S.; Sami, N. (2012) JNNURM: An Opportunity for Sustainable Urbanisation. Indian Institute of Human Settlement. 